\title{
Metacoralidad, itinerarios rituales y "odas que traman" en las tragedias de Esquilo: el ejemplo de Suplicantes ${ }^{1}$
}

\author{
Metachorality, ritual itineraries and "plotting odes" in Aeschylus' tragedies: the example of Supplices
}

Maria del Pilar Fernández Deagustini

Universidad Nacional de La Plata, Argentina

mfernandezdeagustini@fahce.unlp.edu.ar

(iD http://orcid.org/0000-0001-7257-5987

\section{Resumen:}

La hipótesis formulada en este artículo está basada sobre un vasto conjunto de estudios acerca de la naturaleza y función del drama ateniense que han surgido tras el giro performativo. No obstante, mi objetivo es llevar esta teoría a otro nivel, suponiendo la composición deliberada de un arreglo coral integral y transversal de las odas que conforman una tragedia dada. Según esta propuesta, Esquilo, reconocido por la composición de "superodas", organizó sus obras sobre la base de una suerte de circuito, de un "itinerario ritual”, a través del cual las odas urden la trama. Para demostrar la factibilidad de mi hipótesis, analizo como ejemplo la composición equilibrada de las odas inicial y final de Suplicantes.

Palabras Clave: Performance, Odas trágicas, Coro, Itinerario ritual, Suplicantes.

\section{Abstract:}

The hypothesis formulated in this article is based on a vast group of studies about the nature and function of Athenian drama that have arised after the performative turn. Nevertheless, my objective is to take this theory to another level, supposing the deliberated composition of a comprehensive and cross choral arrangement of the odes that shape a given tragedy. According to this proposal, Aeschylus, famous for composing "superodes", organized its plays grounded in a sort of a circuit, a "ritual itinerary", by means of which the odes warp the plot. To demonstrate the feasibility of my hypothesis, I analize as an example the well-balanced composition of Supplices' first and last odes.

KeYwords: Performance, Tragic odes, Chorus, Ritual itinerary, Supplices.

\section{Coralidad en la tragedia (ESQuilea)}

En este artículo propongo continuar una aproximación a los coros trágicos que recoge casi cinco décadas de fructíferas investigaciones, todas ellas atravesadas por el rasgo común del trabajo interdisciplinar. La hipótesis formulada se erige sobre un conjunto de estudios acerca de la naturaleza y función del drama ateniense que han emergido progresivamente desde los años setenta. No obstante, mi objetivo es llevar esta teoría a otro nivel, suponiendo la composición deliberada de un arreglo coral integral y transversal de las odas que conforman una tragedia dada. Según esta propuesta, Esquilo, particularmente reconocido por la composición de "superodas", ${ }^{2}$ organizó sus obras (al menos las conservadas) sobre la base de una suerte de circuito, de un "itinerario ritual", a través del cual las odas urden la trama.

La premisa fundamental (actualmente establecida pero, en otro momento, radical) de lo que se ha conocido como el "giro performativo" es que las palabras escritas transmitidas en nombre de los autores griegos arcaicos y clásicos no solo deben ser abordadas como textos autónomos, tal como los críticos formalistas abogaban, sino como huellas de eventos singulares, que deben ser recreados por el crítico en toda su complejidad. A partir de este giro, se asume que un evento dramático sucede en un cierto espacio, en la presencia de una audiencia dada, y en un contexto social, político y cultural únicos. Por lo tanto, se reconoce que, además de las palabras proferidas por los performers, el texto involucra un amplio espectro de estímulos, tanto visuales como auditivos, que informan la experiencia del espectador. La recreación erudita de un evento dramático 
es, en consecuencia, un proyecto historicista que requiere de un doble enfoque, en el contexto político-social y en la puesta en escena (Goldhill, 1999, pp. 15-16). Asimismo, esta aproximación instala preguntas acerca de la pragmática de la performance (sus efectos cognitivos y emocionales sobre la audiencia), que los estudios más estrictamente enfocados en los autores (y sus "intenciones") tendían a dejar de lado. A continuación, refiero un breve y, sin duda, sesgado recorrido por los que considero los datos fundamentales que introducen mi mirada sobre la coralidad esquilea.

En las últimas décadas del siglo XX y comienzos de este nuevo milenio, la comprensión del drama clásico ateniense ha sido revigorizada por la exploración de los aspectos no verbales de la comunicación dramática, como el espacio (Taplin, 1977; Wiles, 1997; Rehm, 2002), la música (Wilson, 2005) y la danza (Ley, 2007). La inclusión de los certámenes teatrales en los cuales se desarrollaban las celebraciones rituales en honor a Dioniso señalaron secuencias específicas de eventos anteriores y posteriores a la representación de las obras (Goldhill, 1990). También cobraron trascendencia la compleja relación entre drama ateniense y democracia (Vernant-Vidal Naquet, 1988; Griffith, 1995; Rhodes, 2003, entre muchos otros) y las investigaciones sobre la factible composición de la audiencia y abordajes de la recepción dramática (Gentili, 1984; Goldhill, 1994; Hugues, 2008), entre otros aspectos. Sin duda, este giro ha sido representado por la publicación del ya clásico volumen Nothing to do with Dionysos?, significativamente subtitulado Athenian Drama and its Social Context (Winkler and Zeitlin, 1990).

Una de las consecuencias más destacables de estos estudios fue la reevaluación radical de las obras dramáticas como eventos corales, (re) colocando al coro en el centro interpretativo de los “textos” dramáticos. Efectivamente, el giro performativo quebró abruptamente una extensa tradición académica de raigambre aristotélica, ${ }^{3}$ modelada por la idea de que el drama ático alcanzó su perfección cuando se separó de sus orígenes líricos (Poética 1449a10-15). A partir de Atistóteles, la tradición crítica asumió, hasta el cambio de perspectiva promovido por el giro performativo, que la tragedia era "la representación de una acción", cuyas partes fundamentales serían la trama y los personajes, por lo cual la poesía lírica y el espectáculo quedaban relegados a lo accesorio (Poet. $1450 \mathrm{a}$-b); que el coro debía ser considerado como uno de los actores (1456a25) y que la odas corales debían pensarse como interludios, separados de la trama (Poet. 1456a30).

El énfasis contemporáneo de los estudiosos en abordar la tragedia, la comedia y el drama satírico como géneros corales es producto de un nuevo interés en la "coralidad" (chorality), representada por la señera publicación de Calame, Les Choeurs des jeunes filles en Grèce archaïque (1977, traducida al inglés en 1996), que desde entonces se ha expandido desde los coros arcaicos de Esparta y Lesbos hacia las odas de Píndaro y Baquílides, peanes, ditirambos y lamentos (Zimmermann, 1992; Rutherford, 2001; Kowalzig, 2007). ${ }^{4}$ El estudio de Calame sobre los coros femeninos supo capturar en su subtítulo, Morphologie, fonction religieuse et sociale, una percepción central: el coro griego arcaico tenía una función religiosa pero fundamentalmente social, como una expresión holística de la comunidad en la que determinado coro llevaba a cabo su performance. Calame señaló la particularidad más notable de la lírica arcaica, la de ser "poesía de ocasión", implicando que comenzara a ser entendida como un acto social, y reconoció cinco géneros líricos originales: peán, ditirambo, citarodia, trenodia y canción nupcial, aunque admitió la posibilidad de un sexto género, el himno (1996, pp. 74-76). Tras esta (hoy canónica) publicación, el autor ha continuado sus estudios sobre la "coralidad" y la perspectiva performativa, demostrando la proliferación y vigencia de este enfoque. En 2010 ha publicado un volumen colectivo realizado en el marco del GREP (Groupe de récherche ethnopoétique), La voix actée. Pour une nouvelle ethnopoétique, un manifiesto metodológico insoslayable para mi abordaje de la coralidad, que coloca su mirada en el cruce disciplinar entre poesía, música, literatura y etnografía. ${ }^{5}$

Otra publicación que propuso una línea exegética destacable respecto de los coros trágicos ha sido The Hidden Chorus. En ella, Swift (2010) vinculó ritual, lírica y tragedia, estudiando el compromiso de dicho género dramático con la poesía lírica arcaica y, más específicamente, con los valores inherentes a cinco géneros líricos: peán, epinicio, parthéneia, himeneo y treno. Para definir la evocación de los géneros líricos en la tragedia, la autora formuló un modelo de características "nucleares” y “sintomáticas". Según planteó en el 
libro, la característica nuclear de cada uno de estos géneros es su propósito, unido a la ocasión para la cual la canción fue compuesta: "A Greek lyric genre has a purpose to fulfil in the world outside the poem (for example, praising a god, celebrating a marriage) which purely literary genres do not” (2010, p. 15). ${ }^{6} \mathrm{El}$ método busca identificar "alusiones" de la tragedia a la lírica, "interacción genérica”, como acuñó la autora en el libro, en lugar de réplicas de los géneros líricos en las odas (2010, p. 27; 41). Como señaló Swift, los recursos a través de los cuales la tragedia evoca el material lírico varían: relevancia contextual, similitudes performativas o disparadores más específicos, verbales, de imágenes o temáticos pero, sobre todo, vinculados al propósito. Estos guiños habrían permitido al espectador reconocer el género evocado y conectar sus propias asunciones acerca de esta forma de poesía con aquello que veía en escena.

En definitiva, la analogía entre coros dramáticos y no dramáticos ha descubierto las múltiples capas de significado que presentan los coros en la tragedia, tanto dentro como fuera de la ficción. Esto justificó un nuevo énfasis en el contexto ritual de los certámenes dramáticos, que retomó la antigua cuestión acerca de la relación entre drama y ritual, formalmente explorada por los ritualistas de Cambridge en el giro del siglo XX. Tal como otras performances corales eran ofrendas para los dioses, los certámenes trágicos y cómicos eran "performados" en el contexto del festival dedicado a Dioniso. Esta idea de que el contexto del festival infundió los discursos corales con un sentido ritual ha sido la premisa de Henrichs (1994/5). ${ }^{7}$ Los trabajos de Bierl (2009), Gagné- Govers Hopmann $(2013)^{8}$ y Bakker $(2017)^{9}$ también profundizan la tesis de la doble identidad, ritual y ficcional, de los coros dramáticos. Por lo tanto, los estudios recientes sobre la coralidad se incorporan a una concepción del teatro griego clásico enraizada en la tradición platónica, en lugar de la aristotélica. $^{10}$

Como puede advertirse en esta exigua recapitulación bibliográfica, las últimas décadas han propiciado una mejor apreciación de la especificidad de la mímesis coral de la tragedia, sacando al coro de los confines de la ilusión dramática, ubicándolo entre la proyección y la performance y mostrando cómo es capaz de involucrar niveles de referencia simultáneos. En este marco, considero primordial en mi propuesta de análisis sobre la coralidad esquilea la asociación de las odas trágicas con un propósito unido a una ocasión real, derivada de la tradición lírica, dado que presenta dos ventajas: no solo facilita el hecho de aceptar que cada espectador habría podido captar el punto de dicha interacción, sino que refina y resalta el contraste entre lírica trágica y no trágica. ${ }^{11}$ Precisamente, la tesis del trabajo citado de Swift (2010) es que, cuando el coro trágico evoca un género lírico, opera en tres niveles: como coro de ciudadanos atenienses/performers, como personaje dentro de la ficción y como un coro que evoca otras formas de performance coral, aludiendo a los roles que jugaban los coros reales en respuesta a situaciones similares. El título de su libro alude ciertamente a este tercer nivel, que la autora llama "metacoralidad".

En la hipótesis que guía este artículo y constituye el eje de mi actual investigación, la tesis y el método de Swift resultan insoslayables, tanto como aquellos estudiosos mencionados en la reseña previa. No obstante, considero necesario discutir dos cuestiones respecto de The Hidden chorus. En primer lugar, disiento respecto de la exclusión del himno entre los patrones genéricos, ${ }^{12}$ que considero la matriz de composición lírica de las tragedias en general y, en esta ocasión, de Suplicantes en particular. Si bien es cierto que, como afirmó Swift en la sección introductoria del libro, resulta complejo definir estrictamente "himno" como género, es también evidente que las odas trágicas interaccionan con esta especie más que con cualquier otra. En este sentido, el trabajo de Furley y Bremer (2001) sobre los himnos griegos cubre el vacío teórico que el trabajo de Swift deja. ${ }^{13}$ En segundo lugar, y aquí residen el eje y la novedad de mi hipótesis, tal como he observado en mi tesis doctoral (2015: 36), considero que, pese a que Swift ha alcanzado interpretaciones de sumo valor gracias a este enfoque, su interés por demostrar interacciones genéricas entre géneros líricos y drama la ha conducido a analizar odas trágicas aisladas. ${ }^{14} \mathrm{Su}$ método demostró admirablemente la sofisticación que puede tener una oda dada, pero descuidó, en ese planteo indiscutiblemente señero, cuánto esta perspectiva puede agregar a la interpretación de una performance si se consideran las odas desde un punto de vista global, en la que cada una de ellas resulta coherente con una propuesta artística completa. 
En consecuencia, el propósito último de mi contribución es demostrar la riqueza de las conclusiones que puede aportar el enfoque transversal e integrado de las odas de una tragedia, especialmente de las de Esquilo, en las que la coralidad se apropia de la performance a través de la composición de superodas. Según mi hipótesis, en sus tragedias, Esquilo encontró en la coralidad un lenguaje familiar y cotidiano a través del cual pudo eclipsar los límites de la performance dramática. Esta capacidad de ir más allá de la orchéstra concedió a Esquilo la oportunidad de componer vastas odas, pero odas "que traman", que (con) forman el andamio de la propuesta estética, organizadas en itinerarios rituales, para proyectar un circuito coral singular. En particular, el análisis de las odas de Suplicantes a partir de su interacción con los géneros líricos resulta un ejemplo concreto e iluminador respecto de cómo un itinerario coral constituye una herramienta de interpretación excepcional de cada tragedia.

\section{Metacoralidad y “odas que traman" en Suplicantes de Esquilo: el itinerario RITUAL DE PASAJE FEMENINO}

En este apartado procuro exponer conclusiones elocuentes, derivadas del análisis de las odas inicial y final de Suplicantes desde la perspectiva formulada en el apartado anterior, que defino como panorámica, integral y, esencialmente, retrospectiva, dado que la novedad reside en la resemantización que adquiere (en este caso) la primera oda a la luz de la última. La propuesta consiste en demostrar que las odas de esta tragedia de Esquilo traman, desde el comienzo hasta su desenlace, un itinerario ceremonial complejo, que se fundamenta en el ritual que inicia a toda joven en la consumación de su télos: convertirse en mujer.

En primer lugar, recupero sintéticamente algunos datos sobre estas odas, que dialogan con otros trabajos propios sobre cada oda en particular, basados en el análisis filológico- literario:

La oda inicial, entre los versos 1 y 175, inaugura la representación del drama con un himno de procesión primero y, luego, con uno de súplica en el altar. La primera parte, "dinámica" (vv. 1-39), ${ }^{15}$ permite al espectador reconocer al coro que está ingresando al teatro y advertir los elementos cronotópicos necesarios para ubicar la porción del mito que se representa (Fernández Deagustini, 2017a). La marcha anapéstica cubre la distancia entre dos espacios, Egipto y Argos: el de fuera de escena comprende los confusos eventos vinculados con la fuga de las jóvenes asociados al rechazo de la boda con sus primos; el escénico está tomado por la actividad de las suplicantes. El movimiento de ingreso representa entonces la distancia espacial y la trayectoria temporal entre ambos lugares geográficos, un "estado itinerante" entre las dos dimensiones espacio-temporales, imprescindible para el desarrollo de la obra y sustancial en una tragedia de súplica. En esta parte, las protagonistas resaltan su condición de outsiders (ya no las acoge Egipto y aún no las refugia Argos), una condición que exhibe su apariencia física pero contradice la forma de su discurso. Desamparadas, las Danaides se encomiendan a Zeus aphiktor (v. 1), protector de los recién llegados.

En el margen constituido por la costa de la ciudadela, la oda refiere actos simultáneos al discurso: la continuidad de la súplica es la continuidad de la representación, porque a partir del primer verso y hasta el éxodo definitivo del coro en el final de la tragedia, el ritual de súplica se transforma en la performance del espectáculo. Pero la oda inicial se despliega junto a una ópsis desconcertante: las suplicantes, de apariencia bárbara, ejecutan una práctica ritual griega. ${ }^{16}$

En la segunda parte de la oda (vv. 40-175), “estática”, en la que las Danaides ya han alcanzado la inmunidad brindada por el altar público de la ciudad, la interacción con el himno, que constituye el componente persuasivo para obtener el favor de la divinidad, se adecua perfectamente a la ocasión. No obstante, la ejecución del ritual resulta un mecanismo doble y ambiguo, de identificación y de ruptura, dado que, tras la amenaza de suicidio y de blasfemia contra la divinidad sobre el final del canto (vv. 154-175), las Danaides transgreden la norma revelando su naturaleza ambigua, bárbara y helena. Pero lo que me interesa subrayar de 
esta oda es su interacción genérica mixta, ya que la matriz del himno fluctúa con otra, la del treno, que modela el componente emotivo del canto. La impronta trenódica, localizada, según consta en un análisis previo (Fernández Deagustini, 2018a), en los pasajes que comprenden los versos 57-76 y 112-132, genera un efecto perturbador que, además de permitir la composición anímica de la coyuntura, revela el carácter indómito de las Danaides. Precisamente, mi aproximación a la oda inicial a partir del diálogo con la lírica reconoce, en el vaivén genérico, un síntoma de la idiosincrasia de las protagonistas. Su carencia de autocontrol emocional y su incapacidad de sostener el ritual correspondiente y ejecutarlo adecuadamente prefiguran sus futuros excesos. Según este análisis, la perversión del género hímnico y la oscilación anárquica entre dos improntas de ocasiones aparentemente irreconciliables resultan un recurso dramático que permite tanto diseñar el carácter colectivo del coro protagonista como componer el climax germinal de la obra.

La oda final (vv. 1018-1073), como la inicial, está intervenida por la percepción visual. La presencia de un coro subsidiario masculino conformado por los guardias de Argos (vv. 1034-1051; 1054; 1056; 1059, 1061) ${ }^{17}$ y la organización del canto en un intercambio amebeo sugieren una nueva interacción genérica, en esta oportunidad con el himeneo ${ }^{18}$ que, en principio, no parece ser un género apropiado para la ocasión (Fernández Deagustini, en prensa ). No obstante, el impacto de la oda está asociado a la existencia de distintos niveles de lo que llamo "conciencia genérica": las Danaides creen entonar un himno (primero a Argos, luego a Zeus); los espectadores, en cambio, habrían percibido la evocación de las nupcias. Ópsis y composición coral se amalgaman para que la oda final justifique su singularidad cumpliendo múltiples funciones: concluir el asunto de la obra, representando el logro del asilo en el traslado espacial hacia la ciudad; anticipar el núcleo temático de la secuela (el casamiento entre Danaides y Egipcios); introducir un cambio de perspectiva en relación con el tema del matrimonio (aquel con esposos deseables, griegos); ${ }^{19}$ confirmar el grado de obnubilación de las protagonistas sobre el final de la obra; sosegar los ánimos del espectador con una atmósfera festiva y fundamentalmente, gracias a la ironía que implica la ejecución ignorada del canto nupcial, convalidar las expectativas de la audiencia, consciente de la inminencia del verdadero cambio: la consumación de las bodas. Por eso, la clave de la oda final como recurso dramático reside en que el himeneo resulta un género inadvertido para las Danaides, que ofrece la posibilidad de insertar un cambio de perspectiva (masculina y helénica) y proyectar el drama, fundamental en este momento "bisagra", entre el fin de la obra y el comienzo de su continuación. ${ }^{20}$

En términos espaciales, el abandono del recinto sagrado (concomitante con el éxodo) conquistado en la oda inicial traduce el cambio de tópico: aceptadas como metecas (v. 609), las Danaides (también Dánao) dejan de ser suplicantes y su naturaleza femenina ya no puede ser disimulada. De este modo, paradójicamente, laperformance del himeneo resulta oportuna, ya que, como vírgenes, deben casarse para cumplir con su deber.

Sintetizada la interpretación de cada una de las dos odas en forma aislada, propongo exponer las conclusiones a las que permite arribar una mirada holística de la coralidad dramática, que en este caso puede apreciarse si consideramos ambas, inicial y final, como un par combinado y equilibrado, un continuum coral que se fundamenta en el ritual que inicia a toda joven en la consumación de su télos, que es convertirse en mujer. $^{21}$

En primer lugar, considero que el estudio integral de ambas odas no puede perder de vista la importancia de la experiencia teatral, es decir, del componente espectacular. Las dos odas se destacan por la trascendencia de la puesta en escena y la impactante combinación de efectos audiovisuales. Por un lado, en la oda inicial, el dramaturgo genera una contundente primera impresión en el espectador que condiciona su apreciación de todos los sucesos de la obra. La percepción visual revela a un grupo de mujeres junto a un anciano, todos de apariencia bárbara, que irrumpen en escena y se posicionan en un altar con un significativo objeto escénico, los ramos característicos del ritual de súplica griego. La percepción auditiva acompaña al objeto escénico y contrasta con las máscaras, puesto que el coro, exótico, entona un himno de súplica helenizado. Por otro lado, en la oda final, Esquilo deja una categórica última impresión en la audiencia que canaliza el conocimiento del 
espectador sobre los acontecimientos míticos posteriores. El último cuadro escénico reúne a las Danaides y su padre junto con un grupo de hombres. En él, no solo mujeres y hombres, sino bárbaras y griegos, abandonan el altar, el espacio escénico ocupado a lo largo de toda la obra. La percepción auditiva asocia a hombres y mujeres en un canto amebeo que evoca el ritual de boda.

Las conclusiones que formulo en el presente artículo pretenden demostrar que la manipulación del espacio, del tiempo y de la identidad cultural componen y completan un período de transición iniciado en el primer verso de Suplicantes. Esto puede percibirse en el diseño de una continuidad lírica, que implica el itinerario ritual del treno hasta el himeneo. En este sentido, la condición virginal de las Danaides, enmascarada inicialmente por el ritual de súplica, resulta un componente clave no solo de la oda final, sino también de las anteriores. Afirmo esto porque, en términos de motivos e imaginario, existe un notable grado de continuidad entre el himeneo y otro género lírico: el parthéneion. ${ }^{22}$ La transición femenina no debe ser comprendida como un momento singular, de cambio abrupto, sino en términos de una progresión que comienza en la pubertad y termina con el nacimiento del primer hijo (Swift, 2010, p. 249). Considerados de este modo, entonces, parthéneion e himeneo se corresponden con dos etapas de un mismo proceso vital, que en cierto momento se superponen. Suplicantes representa ese momento sobre el final del primer drama de la tetralogía. ${ }^{23}$

El parthéneion es singular como género. Murnaghan (2005, p. 187-188) y Swift (2010, p. 185) definieron con claridad su carácter distintivo, que, a diferencia de otros, concierne particularmente la identidad de sus performers, ya que parte de la función de los parthéneia está conectada con el status de parthénos de quienes cantan. Un parthéneion es, por lo tanto, cualquier canto comprometido con el tema de la transición femenina de la pubertad a la madurez y que, además, juegue un rol fundamental en el ciclo de vida de las jóvenes dentro de la comunidad a la que pertenecen. Por lo tanto, la identidad estatutaria del coro se vuelve tópico durante la ejecución del ritual y resulta tan significativa y constitutiva del género como la ocasión performativa.

Sin embargo, en función de lo expuesto, para alcanzar una interpretación integral de las odas de Suplicantes resulta fundamental reparar en otro componente del ritual del casamiento: el motivo fúnebre (Seaford, 1987, p. 106-107; Rehm, 1994, p. 1-6). Ciertamente, el par boda/ muerte es una característica común de varios ritos de pasaje. En la cultura griega, el mito de Perséfone, cuyo casamiento es literalmente un casamiento con la muerte, prueba fehacientemente la afinidad entre ambos sucesos vitales y, consecuentemente, entre los imaginarios de dos géneros líricos: himeneo y treno. Si se considera esta correlación, apreciable únicamente a partir de una perspectiva holística de la coralidad en una tragedia dada, las odas de Suplicantes potencian sus alcances, las sensaciones y sentidos transmitidos, tras la performance del canto final, es decir, tras una mirada retrospectiva.

Efectivamente, el "falso himeneo" con el que acaba la obra ha sido abordado en relación con el motivo de huida de las Danaides. No obstante, nunca se ha considerado cómo la imaginería de este género arroja nueva luz sobre el material lírico previo, en especial, aquel que explota la interacción con el treno como recurso dramático. ${ }^{24}$ Tampoco ha sido analizado este material como urdimbre medular de la trama trágica.

Tal como he señalado en la síntesis de la performance de ambas odas en el inicio de este apartado, la oda inicial parece asociarse, a priori, al ritual fúnebre, especialmente por la insinuación del suicidio colectivo (vv. 154-160). Precisamente, según mi interpretación, en el final del drama, la performance de la oda final descubre que ese "elemento trenódico" (vv. 57-76; 112-132) es una de las maneras en las que se presenta la imaginería del período previo al matrimonio, propio de las parthénoi, las jóvenes en edad de casarse. Se trata, por lo tanto, de la inauguración de un itinerario coral que despliega el ritual de pasaje femenino. Esta hipótesis se justifica sobre la base de tres aspectos fundamentales:

1. Espacio. Si se considera la manipulación de los espacios escénicos en la tragedia, la circunstancia transitoria de las suplicantes resulta un dato valioso, pues los períodos transicionales femeninos usualmente implican pasar cierto tiempo en una condición simbólicamente salvaje o recluida, removida de los lazos cívicos o familiares. ${ }^{25}$ Justamente, las Danaides ejecutan sus cantos mientras 
permanecen retiradas en el altar, en el alejado espacio de la costa. De este modo, como parthénoi cuyo desarrollo hacia la madurez ha sido interrumpido, se mantienen en un espacio marginal, de aislamiento. No es casual, entonces, que la performance del himeneo se circunscriba al momento preciso en el que se dirigen a la ciudad, sugiriendo el retorno a los lazos sociales tanto como la completitud del rito de pasaje interrumpido en el inicio del drama.

2. Compañía. Resulta estratégica la explotación de la compañía (masculina) de las protagonistas, ya que las parthénoi deben abandonar su casa paterna para casarse. Estas parthénoi ingresan a escena en la oda inicial acompañadas por Dánao, su padre. Por lo tanto, la presencia escénica de este personaje silente resulta otro indicio de ese paréntesis en el período de desarrollo. En el ritual nupcial, el primero de los pasos era la ceremonia del compromiso, que implicaba el acuerdo que se consumaba entre el padre u otro pariente masculino y el futuro marido. La joven simplemente pasaba pasivamente de la casa de un hombre a la de otro. En Suplicantes, Dánao, en el comienzo de la obra, denuncia la conducta ilícita de los hijos de su hermano y niega la posibilidad del matrimonio de sus hijas con estos; en cambio, sobre el final, escolta al coro mixto hacia la nueva ciudad. Durante la performance de la oda final, el recuerdo del ingreso del padre junto a las jóvenes habría cobrado una relevancia trascendental para el espectador, dado que las Danaides se retiran acompañadas por un grupo de hombres (además, griegos). ${ }^{26}$

3. Ocasión. Según la definición de treno como canto de muerte real, la oda inicial de Suplicantes se ajusta a la ocasión primaria, en tanto las Danaides albergan la posibilidad de morir si su súplica no es aceptada, que se expresa en las múltiples amenazas de suicidio proferidas. Pero además, la interacción con el treno se adecua a otra ocasión, la de la muerte simbólica de la virgen.

Este último punto requiere de una atención especial, puesto que es importante recordar que, según el posicionamiento teórico que guía este análisis, la interacción entre odas trágicas y géneros líricos apela a ciertos principios culturales compartidos. Desde esta perspectiva, el género trenódico con el que interactúa la oda inicial se subvierte para crear un efecto perturbador. Como género lírico, si bien responde a un evento angustiante, no se liga al propósito específico para el que ha sido creado, es decir, el ritual funerario. Por ello, el canto socava el fin reconfortante del lamento e instala, en cambio, un clímax inquietante, apropiado para los eventuales sucesos de la obra. La interpretación de la tragedia que emerge a través de la lente de la lírica se arraiga de este modo en su contexto social y cultural. Por eso, aunque la oda inicial desobedezca las convenciones genéricas y proponga una interacción lírica mixta, con el himno y el treno, que a primera vista parece incongruente, abordada desde la perspectiva etnopoética descubre otros múltiples sentidos. En primer lugar, la muerte a la que cantan las Danaides es, en sentido figurado, la muerte de la virgen, de la vida bajo la protección de la familia de origen y, fundamentalmente, de la figura paterna. En segundo lugar, la alusión a la muerte es un guiño al espectador que busca anticipar de los futuros sucesos míticos, es decir, como ironía trágica. Desde este punto de vista, el tópico tradicional se altera y la muerte figurada de la novia (las Danaides) anuncia la muerte efectiva del novio (los hijos de Egipto), en la misma noche de bodas. Por último, la muerte es una advertencia sobre las consecuencias que el rechazo de la insitución matrimonial puede acarrear a nivel público, para la comunidad, más allá de la circunstancia inicialmente privada que plantean Dánao y sus hijas. ${ }^{27}$ Como señalan los guardias argivos en el canto amebeo de la oda final, el rechazo de la unión con el hombre implica una perversión del orden natural (la obligación femenina de dar vida y perpetuar la familia) que puede (paradójicamente) traer solamente la muerte.

Según lo expuesto, la oda final de Suplicantes permite demostrar y comprender cómo el treno de la oda inicial puede ser usado para decodificar un patrón normativo cultural más amplio: enmarañado con la práctica extranjera de un ritual local que se tiñe de excesos, se asocia a un hito fundamental de la vida femenina, el casamiento. Por eso, tanto la rareza compositiva de esta oda como su disposición sobre el final de la obra la vuelven extremadamente enfática: el lamento de la futura novia se convierte en un filtro para 
comprender a las Danaides (como mujeres, extranjeras y suplicantes) que simboliza la híbris que condicionará la conocida destrucción de las protagonistas. Como las Danaides no poseen la virtud griega de la mesura, fundamental en la ejecución del treno según la legislación del siglo $\mathrm{V}$, su extraordinario lamento, fuera de los límites de la regulación social, debe ser explicado desde otro punto de vista, como un ritual griego puesto en práctica por jóvenes extranjeras (Fernández Deagustini, 2018a). ${ }^{28}$

El análisis realizado demuestra que Suplicantes pone en escena una coyuntura común a toda mujer ateniense de la época clásica: ${ }^{29}$ el tránsito de la niñez a la madurez a través de la ceremonia del casamiento. Sin embargo, no se trata de un hecho cotidiano, sino de un acontecimiento único, el paso hacia una nueva vida. ${ }^{30}$ En circunstancias ordinarias, la proximidad del matrimonio se presenta con características ambiguas para la novia, pues la transición contiene tanto elementos positivos como negativos. Por un lado, significa aislamiento, separación de los suyos, culminación de una etapa bajo la protección paterna, ${ }^{31}$ abandono del hogar, una ocasión de resquemor y ansiedad comparable con la muerte para cualquier mujer joven. No obstante, se trata también de una materia de ceremonia y festejo en el marco de la comunidad. Como coinciden en señalar Seaford y Zeitlin, ${ }^{32}$ la relación entre ambos aspectos es singularmente delicada: la tendencia negativa no debe ser soslayada pero, eventualmente, debe ser superada, ya que la boda expresa el dominio de la cultura sobre la naturaleza.

En definitiva, consideradas a partir de su interacción con los géneros líricos, las odas inicial y final de Suplicantes conforman un par combinado y equilibrado de canciones, diseñando el marco de un período de transición que conduce a las protagonistas hacia la consumación de su tlos. La continuidad lírica, desde el par treno/parthéneion hasta el himeneo, descubre un proceso, una progresión temporal que pone en escena la proximidad cada vez mayor de las protagonistas a la concreción de su inevitable destino femenino. ${ }^{33}$ La perseverancia del tono hímnico a lo largo de la oda final no hace más que demostrar la obstinada resistencia de las Danaides para cumplir con el imperativo divino y social del matrimonio. Las jóvenes temen y rechazan las bodas tal como toda parthénos, pero resulta innegable que vulneran el patrón cultural ordinario: el elemento adverso en relación con el matrimonio, que compone el Leitmotiv de las odas corales, prevalece inflexiblemente sobre el favorable, desde el comienzo hasta el final de la tragedia. Con “odas que traman”, Esquilo transforma una situación ordinaria en conflicto trágico.

\section{ConClusión}

En las odas de Suplicantes de Esquilo, las Danaides reúnen dos funciones incompatibles solo en apariencia, coro y protagonismo, porque actúan mientras cantan, es decir, promueven un cambio en la acción dramática al desempeñar distintos momentos coyunturales de un itinerario ritual. La formación coral de parthénoi arriba en carácter de suplicante a la costa de Argos y desempeña, hasta el momento de su traslado definitivo a la ciudad, un itinerario ceremonial complejo, inaugurado por el himno pero sesgado por la ejecución de un ritual de pasaje continuo, del treno/parthéneion hasta el himeneo. Por su doble condición de vírgenes suplicantes y por sus actos de ejecución ritual, las Danaides resultan el agente insustituible de la performance trágica. La integración del himno, el treno/parthéneion y el himeneo en la performance resulta un recurso de excelencia que el dramaturgo ha sabido explotar, jugando con la ocasión ritualizada y las expectativas de la audiencia respecto de los géneros evocados para enriquecer la comprensión de lo que se habría percibido en el escenario. Según propuse en esta publicación, el deliberado uso de los géneros líricos reconocidos por los espectadores contemporáneos como parte del entramado del espectáculo constituye un logrado artilugio que prueba que, en Suplicantes, las odas resultan un recurso estratégico de la composición dramática.

Como ha sido expuesto, vincular géneros líricos y odas trágicas es una herramienta exegética de demostrada capacidad y de tendencia actual en el campo de la filología. El estudio de las odas que propongo es filológico y etnopoético (Calame, 2010) porque coloca en primer plano el influjo de la interacción genérica sobre los 
acontecimientos. En este sentido, el énfasis en el aspecto ritual del coro tiene como objetivo demostrar cómo las superodas compuestas por Esquilo en esta tragedia en particular resultan una instancia de cambio en la trama pero también estratégica en el montaje de la performance, constituyendo, por los géneros líricos y los principios rituales con los que pueden ser asociadas, no solo acción, sino un recurso fundamental de la puesta y apuesta en escena. Por lo tanto, cada oda ocupa una posición decisiva en el desarrollo de la obra, tanto desde los sentidos que transmite su vínculo dual con el ritual y la ocasión en la que se desarrolla como desde las emociones, evocaciones y efectos que promueve, on y offstage, en tanto factor fundamental en la composición de un espectáculo multimediático.

En este marco interpretativo que cuestiona la tradición aristotélica, la composición de la coralidad constituye el foco de interés, dado que se asume como coherente con la propuesta artística, como agente fundamental en la construcción de sentidos, percepciones y espectáculo. En la composición, disposición e integración de las odas, los géneros líricos perfilan o rematan giros en la recepción de la performance, porque el lenguaje de estos géneros era uno de los códigos de la vida cotidiana de los espectadores. Por lo tanto, este trabajo de análisis se propone como parte de un proyecto más amplio, extensible en mi caso a las otras tragedias esquileas conservadas, pero también, posiblemente, a las obras de los otros dramaturgos. La mirada transversal e integradora de las odas permite, según mi punto de vista, avanzar sobre problemas actuales de la filología clásica tanto como sobre objetos de estudio de otras áreas, prometiendo arrojar luz sobre cuestiones como el lugar de la mujer en el siglo $\mathrm{V}$ y su desempeño en el ritual, la función de los géneros líricos en la cotidianeidad clásica, el compromiso emocional que cada género vehiculizaba, y, sobre todo, la tarea de composición "multimediática" (Mota, 2008) del dramaturgo y posibles conjeturas sobre su estilo.

En definitiva, se trata de demostrar que las tragedias (de Esquilo) no solo no abusan de la lírica coral, sino que su plétora lírica permite abordarlas desde una perspectiva con un giro novedoso, el recorrido a través de la voz de sus coreutas, una voz que sigue una organización deliberada y coherente del dramaturgo. La predominancia lírica en las obras de Esquilo constituye una decisión artística, el aprovechamiento al máximo de un recurso importante y versátil del género. De este modo, las odas se nos descubren como una llave de acceso para una interpretación integral de la obra, como una aproximación productiva para la construcción del espectáculo en su contexto efectivo, que entiende su peculiaridad más sobresaliente, el coro, en términos de excelencia. En definitiva, resulta incontrovertible reconocer la importancia de los contextos performativos para la literatura griega, que ha trazado el camino para una nueva manera de entender no solamente los géneros líricos, sino también otros como la tragedia que, por su carácter mimético, compromete un entramado contextual más complejo, que nos convoca a continuar repensando la oralidad.

\section{REFERENCIAS}

Andújar, R., Coward, Th. y Hadjimichael, Th. (2018). (Eds.) Paths of Song. The Lyric Dimension of Greek Tragedy. Berlin, Boston: The Gruyter.

Bakker, E. J. (2017). Mnemosyne Supplements. Authorship and Greek Song: Authority, Authenticity and Performance. Leiden, Boston: Brill.

Bierl, A. (2009). Introduction. The Choral Dance and Song as Ritual Action: A New Perspective. En Ritual and Performativity. The Chorus in Old Comedy. Cambridge, London: Harvard University Press. Recuperado de https://chs.harvard.edu/CHS/article/display/4514.introduction-the-choral-dance-and-song-as-ritual-actio n-a-new-perspective

Bowen, A. J. (2013). Aeschylus Suppliant Women. Edited with a translation, Introduction and commentary. Oxford: Aris Phillips Classical Texts.

Calame, C. (1994/5). From Choral Poetry to Tragic Stasimon: The Enactment of Women's Song. Arion, 3(1), 136-154. 
Calame, C. (1996 trad. de 1977). Choruses of Ancient Women in Greece: Their Morphology, Religious Roles and Social Functions. Lanham, Boulder, New York, London: Rowman \& Littlefield Publishers.

Calame, C. (1999). Performative Aspects of the Choral Voice in Greek tragedy: Civic Identity in Performance. En Goldhill, S. y Osborne, R. (ed.) Performance Culture and Athenian Democracy (pp. 125- 153). Cambridge: Cambridge University Press.

Calame, C. (2017). La tragédie chorale: poésie grecque et rituel musical. Mondes anciens. Paris: Les Belles Lettres.

Calame, C., Dupont, F., Lortat-Jacob, B. y Manca, M. (2010). La voix actée. Pour une nouvelle ethnopoétique. Paris: Éditions Kimé.

Fernández Deagustini, M. del P. (2015). Suplicantes de Esquilo. Una interpretación (Tesis doctoral). La Plata. Recuperado de http://sedici.unlp.edu.ar/handle/10915/51947.

Fernández Deagustini, M. del P. (2016). Lo femenino en la literatura ateniense del periodo clásico. Suplicantes de Esquilo: la mujer ruiseñor. Phoînix, 22(1), 51-71.

Fernández Deagustini, M. del P. (2017a). Identidad ritual y performance: un análisis de los primeros dos versos de Suplicantes de Esquilo. Caliope, 34, 4-22 (separata 4).

Fernández Deagustini, M. del P. (2017b). ¿Anellenóstolon? La escena de reconocimiento entre las Danaides y Pelasgo en Suplicantes de Esquilo, 234-325. Nova Tellus, 35(2), 45-59.

Fernández Deagustini, M. del P. (2018a). Suplicantes de Esquilo. Ritual de mujeres migrantes: la oda inicial como performance de la alteridad. En De Sousa Lessa, F. y Zecchin, G. (comp.) Literatura y sociedad en la Grecia antigua (pp. 65-84). Río de Janeiro: Mauad Editora.

Fernández Deagustini, M. del P. (2018b). Drama, lírica e interacción genérica: la oda central de Suplicantes de Esquilo (625- 709). Revista de Estudios Clásicos, 45, 101-126.

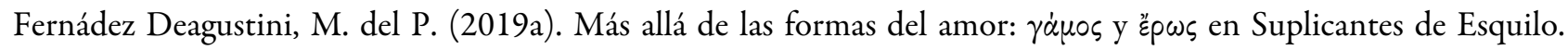
Euphrosyne, XLVII, 31-52.

Fernández Deagustini (en prensa). Cómo hacer cosas con canciones: ironía trágica y coralidad en la oda final de Suplicantes de Esquilo.

Fernández Deagustini, M. del P. (2019b). Historia, mito y autobiografía: "el tiempo de Ío" en Suplicantes de Esquilo. Presentado en las IX Jornadas de Estudios Clásicos y Medievales Diálogos Culturales. "Orígenes, ciclos, edades", UNLP, 28 al 30 de agosto de 2019. Inédito.

Fernández Deagustini, M. del P. (2019c). Relaciones de poder y sexo en Suplicantes de Esquilo. La unión idealizada de Zeus e Ílo. Presentado en VII Jornadas de las Mujeres y Problemáticas de Género, Universidad de Morón, 27 y 28 de septiembre de 2019. Inédito.

Furley, W. y Bremer, J. M. (2001). Greek Hymns. Volume I. The Texts in Translation. Tübingen: Mohr Siebeck.

Gagné, R., y Govers Hopman, M. (2013). Choral Mediations in Greek Tragedy. Cambridge: Cambridge University Press.

Gentili, B. (1984, 1996). Poesía y público en la Grecia antigua. Sirmio- Quaderns Crema: Barcelona.

Goldhill, S. (1990). The Great Dionysia and Civic Ideology. En Winkler, J. J. - Zeitlin, F. Nothing to do with Dionysos? Athenian Drama in its Social Context (pp. 97-129). Princeton: princeton University Press.

Goldhill, S. y Osborne, R. (Ed.) (1994). Art and Text in Ancient Greek Culture. Cambridge: Cambridge University Press.

Goldhill, S. y Osborne, R. (Ed.) (1999). Performance Culture and Athenian Democracy. Cambridge: Cambridge University Press.

Griffith, M. (1995). Authority Figures. En Gregory, J. (ed.) A Companion to Greek Tragedy (pp. 333-352). Malden, Oxford, Carlton: Blackwell Publishing.

Henrichs, A. (1994/5). Why should I dance? Choral Self Referenciality in Greek Tragedy. Arion, 3(1), 56-111.

Henrichs, A. (1996). Dancing in Athens, Dancing on Delos: Some Patterns of choral Projection in Euripides. Philologus, 140, 48-62.

Hugues, A. (2008). Ai Dionysiazusai: Women in Greek Tragedy. BICS, 51(1), 1-27. 
Kowalzig, B. (2007). Singing for the Gods: Performances of Myth and Ritual in Archaic and Classical Greece. Oxford: Oxford University Press.

Ley, G. (2007). The Theatricality of Greek Tragedy. Playing Space and Chorus. Chicago, London: Chicago University Press.

Mota, M. (2008). A dramaturgia musical de Ésquilo: investigações sobre composição, relização e recep̧̧ão de fiç̧öes audiovisuais. Brasília: Editora UnB.

Murray, P., y Wilson, P. (2004). Music and the muses. The culture of Mousiké in the Classical Athenian City. Oxford: Oxford University Press.

Murnaghan, Sh. (2005). Women in groups: Aeschylus Suppliants and the female choruses of greek tragedy. En Pedrick, V.- Oberhelman, S. (eds.). The soul of Tragedy. Essays on Athenian Drama (183-198). Chicago-London: University of Chicago Press.

Parry, H. (1978). The Lyric Poems of Greek Tragedy. Toronto-Sarasota: S. Stevens.

Rehm, R. (1994). Marriage to Death. The Conflation of Wedding and Funeral Rituals in Greek Tragedy. Princeton: Princeton University Press.

Rehm, R. (2002). The Play of Space. Spatial Transformation in Greek Tragedy. Princeton: Princeton University Press. Ryzman (1989). The psychological role of Danaus in Aeschylus' Supplices. Eranos, LXXXVII, 1-6.

Rhodes, P. J. (2003). Nothing to do with Democracy: Athenian drama and the polis. JHS, 123, 104-119.

Rutherford, I. (2001) Pindar's Paeans. A reading of the Fragments with a Survey of the Genre. Oxford: Oxford University Press.

Seaford, R. (1987). The tragic wedding. JHS, 107, 106-130.

Sommerstein, A. H. (2008). Aeschylus. Persians, Seven against Thebes, Suppliants, Prometheus Bound. Cambridge, Massachusetts, London: Loeb Classical Library.

Swift, L. (2010) The Hidden Chorus: Echoes of Genre in Tragic Lyric. Oxford-New York: Oxford University Press.

Swift, L. (2018). Competing Generic Narratives in Aeschylus' Oresteia. En Andújar, R., Coward, Th. y Hadjimichael, Th. (Eds.) Paths of Song. The Lyric Dimension of Greek Tragedy (pp. 119-136). Berlin, Boston: The Gruyter.

Taplin, O. (1977) The Stagecraft of Aeschylus. The Dramatic Use of Exits and Entrances in Greek Tragedy. Oxford: Clarendon Press.

Taplin, O. (1978) Greek Tragedy in Action. London and New York: Routledge.

Torres, D. (Ed.) (2017). La himnodia griega antigua. Culto, performance y desarrollo de las convenciones de género. Buenos Aires: Colección Saberes de la Facultad de Filosofía y Letras de la Universidad de Buenos Aires.

Vernant, J. y Vidal-Naquet, P. (1988). Myth and Tragedy in Ancient Greece. New York: Zone Books.

Wiles, D. (1997). Tragedy in Athens. Performance Space and Theatrical Meaning. Cambridge, New York, Melbourne: Cambridge University Press.

Wilson, P. (2005). Music. En Gregory, J. (ed.). A Companion to Greek Tragedy. London: Blackwell Publishing.

Winkler, J. y Zeitlin, F. (1990). Nothing to do with Dionysos? Athenian Drama in its Social Context. Princeton: Princeton University Press.

Zimmermann, B. (1992). Dithyrambos: Geschichteeiner Gattung. Göttingen: Vandenhoeck \& Ruprecht.

\section{Notas}

1 Considero necesario aclarar que el presente artículo se cimenta sobre dos pilares en mi trayecto de investigación: por un lado, la propuesta teórica respecto de la coralidad en la tragedia esquilea en general conforma mi campo de estudio actual, parte del cual desarrollo en el marco del Proyecto colectivo "Del treno al epitafio: poética del lamento funeral en la Literatura Griega Clásica. Inflexiones" (H 861, UNLP). Por el otro lado, el ejemplo de Suplicantes está basado sobre una de las secciones que han constituido mi tesis doctoral (UNLP, 2015). No obstante, esta conclusión que aquí expongo y que constituyó indudablemente el germen para enunciar una hipótesis mucho más amplia, abarcadora del teatro de Esquilo que conocemos, permanecía aún inédita. Ha sido presentada como ponencia en la Universidad de Morón en el 
año 2017 en las VI Jornadas de Historia de las mujeres y problemáticas de género, por su exposición del ritual de pasaje femenino. Creo que la publicación de este Dossier sobre los coros en Esquilo constituye el kairós para dar a conocer tanto esta lectura (de una parte) de Suplicantes como de mi conjetura y ocupación más recientes en cuanto a los coros que conforman las tragedias conservadas de este admirable dramaturgo. El primer tramo de mi proyecto individual se titula "La lírica, recurso estratégico de la composición dramática en las obras de Esquilo. Una interpretación etnopoética de las odas trágicas de coros femeninos de naturaleza humana: Los siete contra Tebas, Suplicantes y Coéforas”.

2 Según supo señalar Parry (1978, pp. 50-51), gran cantidad de las partes corales compuestas por Esquilo en las obras conservadas pueden clasificarse como "superodas" o, incluso, "odas masivas", es decir, aquellas que superan holgadamente los cien versos de extensión.

3 Los argumentos genéticos acerca de los orígenes del drama ático ocuparon una posición singular en la reevaluación de la tragedia y la comedia como géneros corales. Aristóteles afirmó en Poética que la tragedia nació de los líderes del ditirambo y la comedia de los líderes de los sátiros, que Esquilo incrementó el número de actores de uno a dos, redujo las partes corales y dio al diálogo el papel fundamental, y que el tercer actor fue incluido por Sófocles (Poet. 1449a 10-15). En el programa aristotélico, estas afirmaciones soportan un argumento que subestima la importancia del coro.

4 Esto no significa que no había interés sobre las odas trágicas antes del giro perfomativo de los '90 (en 1970 se publicó The Chorus of Greek Drama Within the Light of the Person and Number Used de Kaimio; en 1980 Burton estudió los coros en las tragedias de Sófocles). No obstante, estos estudios consideraron las odas desde un punto de vista literario, independientemente de su relación con otros géneros líricos o con el ritual.

5 La etnopoética, como mirada científica, instaló la cuestión de la clasificación de los géneros según las diferentes culturas. Se propone acabar con el dictado del enunciado erigido como "texto", pretendidamente objetivo y autónomo, dotado de un sentido intangible. Ese sentido se entiende, por el contrario, como una construcción que se hace en la recepción (experiencia teatral o literaria). Esta aproximación obliga a escaparse de los esquemas habitualmente clásicos, como el comunicacional (emisor/receptor; productor/consumidor) o el de la taxonomía fija de los géneros anterior al evento de la enunciación. Como consecuencia, las odas corales deben ser analizadas teniendo en cuenta que: 1. los participantes de la performance son co-enunciadores que contribuyen, cada uno a su manera, con la significación cultural de los respectivos eventos enunciativos; 2. un enunciado verbal no puede por sí mismo constituir un género. Es su explotación en la ocasión de un evento ritual dado (lugar, tiempo, estatuto de sus participantes, motivación, etc.) lo que lo constituye eventualmente como un género reconocido por la comunidad. Calame ha continuado este estudio en La tragédie chorale: poésie grecque et rituel musical. Mondes anciens (2017).

6 Evidentemente, el trabajo de Swift continúa la línea de Calame, pues el cometido "social" es el que dicta los valores inherentes a cada género.

7 En un artículo posterior, Henrichs (1996) desarrolló el concepto de "proyección coral”, refiriéndose a la capacidad del coro de representar otras danzas y coros distantes, como extensión de su propia performance en el aquí y ahora de la puesta en escena. Para Henrichs, la dimensión ritual de la experiencia teatral, tanto diacrónica (como memoria de sus orígenes en la celebración de culto coral), como sincrónica (como diálogo directo con las prácticas e imaginarios rituales contemporáneos a la performance), descansa detrás de la capacidad complementaria del coro dramático para proyectarse y reflejarse a sí mismo.

8 La tesis que impulsa el volumen de Gagné y Govers Hoppman es que el coro en el drama antiguo es en gran medida ritual. Las editoras retornan, por lo tanto, a una teoría que, como señalan, por mucho tiempo ha sido forzadamente "olvidada", tras los excesos de los ritualistas de Cambridge, específicamente por su tesis de que el origen del drama está en el ritual. A partir de ello, conectan los resultados con la danza dramática coral, considerando, por un lado, los patrones repetitivos de movimiento; el vínculo de la canción con el mito, es decir, con las narrativas tradicionales que resultan relevantes para la unidad de la comunidad; la naturaleza de la canción coral como acto de habla "autoritativo"; la reactualización del mito en el ritual. Por otro lado, proponen atender a la autorreferencialidad que el coro realiza de su actividad en la orchéstra. Como resultado, según las editoras, surge un arreglo típico de ritual, en el que el coro representa a un grupo selecto de la comunidad y él mismo retrata esto a la manera de un "microcosmo" de la polis, propuesta que, según considero, puede advetirse en el arreglo coral de Suplicantes de Esquilo.

9 Este volumen es el resultado de otra red que, como el mencionado GREP, conglomera a reconocidos académicos en el estudio de la canción coral griega, la Network for the Study of Archaic and Classical Greek Song. En 2017, Bakker ha editado Authorship and Greek Song: Authority, Authenticity and Performance, cuya publicación constituye una prueba más de la actualidad de los estudios performativos y corales.

10 Wiles (1997, p. 87): "Plato, unlike Aristotle, grew up in Athens and experienced fifth-century drama. He conceives tragedy as an event rather than a text”. El autor amplía este punto de vista tanto en la introducción de su libro (pp. 6-9) como a lo largo del capítulo cuarto.

11 Tal como señaló Swift en la introducción de su libro, muchos de los problemas que rodean a los géneros líricos resultan de una aproximación excesivamente rígida a la categorización. Las dificultades propias de este tipo de abordaje son dos: 1. el escaso corpus conservado impide encontrar una aproximación empírica; 2. las teorías helenísticas antiguas son poco 
confiables porque raras veces son acerca de los poemas que conservamos. En la aproximación a la coralidad trágica que propongo llevar a cabo, tal como Swift, centro la atención sobre las "alusiones" genéricas que encontramos en las odas trágicas de los coros sin que ello signifique hacer una teoría acerca de la lírica o, aun menos, una taxonomía.

12 Swift (2010, pp. 20-21) sostiene que "himno" engloba otros subgéneros: "There are clearly continuities and conventions within the category of religious song, and it is therefore posible to describe something as 'hymnic'. Nevertheless, it seems difficult to be more specific about hymnos as a genre, and it is striking that Furley and Bremer's book on Greek hymns includes a range of religious songs drawn from a number of contexts (including paianes)."

13 Furley y Bremer (2001) emparentaron estrechamente al himno con la súplica, ritual central en las tragedias de Esquilo, y evidentemente en Suplicantes. Ciertamente, resulta indiscutible el hecho de que los cinco géneros rescatados por Swift están ligados a propósitos concretos: el canto de curación o celebración de la seguridad obtenida (peán), el de victoria (epinicio), el correspondiente a un rito de pasaje femenino (parthéneion), la celebración del matrimonio (himeneo) y el canto funeral/ de lamento (treno). Pero en las tragedias esquileas, si bien las odas presentan interacciones en mayor o menor grado con estos géneros, todas se componen para agradar a una divinidad y obtener un favor a cambio, definición que corresponde precisamente a la etiqueta de "himno". Quizás por eso Calame (1977/ 1996) dudaría en agregarlo como un género más. Precisamente, considero necesario destacar como libro de consulta respecto del género himno la publicación de Torres (2017).

14 Creo necesario señalar que, algunos años después de que realicé esa objeción a la propuesta de Swift (reconociendo el valor su propuesta) y demostré las posibilidades de desarrollo que tenía su planteo en el análisis de las odas de una obra dada como Suplicantes, pero con muchos años de distancia respecto de la publicación de The Hidden Chorus (2010), la autora haya actualizado su propio trabajo con un análisis de la interacción genérica en Orestíada (2018). Se trata de un capítulo de la reciente compilación de Andújar, Coward y Hadjimichael (2018) sobre la dimensión lírica en la tragedia griega. La publicación de este libro, por un lado, prueba la actualidad de este campo de investigación y, por el otro, convalida a través de su título, The Paths of Song, la tesis probada por mí en 2015, que ahora propongo expandir a todas las obras conservadas de Esquilo.

15 En Fernández Deagustini (2017a) expuse detalladamente la performance de la ritualidad desplegada en esta oda a través del análisis filológico-literario exclusivo de los primeros dos versos, que inauguran la obra. Para detalles sobre el análisis de esta oda y una interpretación a partir de las interacciones genéricas, cf. Fernández Deagustini (2018a).

16 Cuando el rey Pelasgo se presenta en el altar al encuentro de las recién llegadas, sus primeras palabras son sustanciales, porque dan cuenta de una primera impresión, exclusivamente visual, de las Danaides, equiparable con la experimentada por el espectador. A los ojos del rey, las recién arribadas suplicantes no parecen helénicas (vv. 234-245). Pelasgo advierte en su discurso que las Danaides pretenden comportarse como griegas, pero no lo logran. Para un análisis detallado de este encuentro entre griegos y "bárbaros”, cf. Fernández Deagustini (2017b).

17 El manuscrito que ha transmitido Suplicantes no explicita cambio de hablante durante la performance de la oda final, pero la interpretación del texto sugiere la presencia de una segunda voz. Las hipótesis para descubrir su identidad han dado lugar a las más variadas propuestas: la participación de dos semicoros, de un coro secundario, o bien, de un actor. Para un estado de la cuestión detallado, cf. Fernández Deagustini (2015, pp. 93-100); para una síntesis y fundamentación de mi posicionamiento, cf. Fernández Deagustini (en prensa). Las dos ediciones con las que elijo trabajar en mis interpretaciones de Suplicantes, Sommerstein (2008) y Bowen (2013) coinciden en considerar que esta segunda voz implícita habría sido la de un coro secundario de guardias argivos.

18 Seaford ha sido el primero en señalar la trascendencia de la performance mixta en Suplicantes (1987, p. 114); Swift (2010, pp. 279-297) también ha tomado esta oda como ejemplo para ilustrar la interacción genérica entre tragedia y lírica. Como señalé, la autora no integra su análisis con el de las otras odas del drama.

19 Sobre la estrecha y compleja relación entre sexualidad y política en Suplicantes, cf. Fernández Deagustini (2019a).

20 La cuestión acerca de la composición tetralógica a la que correspondería Suplicantes es extensa y, ciertamente, todavía conjetural. Asimismo, es problemática en tanto ha sesgado las interpretaciones de la obra que conservamos (Fernández Deagustini, 2015, pp. 12-27). No obstante, el acuerdo de los estudiosos respecto de la integración en una tetralogía conformada por Egipcios, Danaides y Amímone como drama satírico es prácticamente unánime. No solo me alineo en ese consenso, sino que considero que la mirada hacia las interacciones genéricas agrega un argumento sólido a la hipótesis sobre esta concatenación de obras, tal como propongo en Fernández Deagustini (en prensa).

21 El itinerario ritual que pone en escena Suplicantes de Esquilo, que supone, según mi hipótesis, un continuum ritual, no sigue un recorrido "rectilíneo", desde la primera hasta la última oda. Por el contrario, compone un trayecto sinuoso y complejo, que he desentrañado a partir del análisis de cada una de las odas en particular. En la segunda oda coral, examiné recientemente (Fernández Deagustini, 2019b y 2019c, aún inéditos) que, frente a la actitud ultrajante de los Egipcios, las protagonistas componen y cantan un relato personal de otra unión, aquella fundacional entre Ío y Zeus, y cómo, en esa versión, los sucesos del pasado remoto aparecen sesgados, porque soslayan la violencia. Por otro lado, propuse que la tercera oda coral (Fernández Deagustini, 2018b), que intersecciona con el peán, integra el foco neurálgico de la tragedia, funcionando como pivote de una fugaz cadena de sucesos. La mejor y la peor noticia para las protagonistas resultan el 
marco de este momento coyuntural. Antes de la oda, un mensaje que involucra al salvador; después, uno que involucra al perseguidor, con lo cual la infelicidad-felicidad-nueva infelicidad entorpece el devenir de la acción de una manera única. En cuanto a la cuarta oda (Fernández Deagustini, 2016), el sustrato trenódico, presente también en la oda inicial, se descubre en un tono unívoco y monocorde, que prefigura los excesos de las protagonistas y sumerge al espectador en el pánico que caracteriza ese momento de la trama, en el que las Danaides se encuentran efectivamente acorraladas por sus primos.

22 Muchos estudiosos consideran que el parthéneion es una categoría lírica. Calame (1996) rechaza el término como nombre genérico (pp. 18-20) y, en cambio, divide los coros ejecutados por mujeres jóvenes en categorías determinadas por otras funciones, incluyendo, por ejemplo, al himno y el ditirambo (pp. 145-167). Por el contrario, entiendo que, como señala Swift (2010, p. 174), este grupo de cantos se asocia a circunstancias reconocibles que permiten delimitarlo como una especie lírica particular.

23 Murnaghan ha realizado otro importante aporte en su artículo sobre los coros femeninos de la tragedia griega. Fundamentada en el estudio de Calame (1996), que propone el ritual de iniciación como uno de los contextos más frecuentes del coro femenino, la autora afirma que la situación dramática de las Danaides refleja el escenario de iniciación típico, en el intensificado idioma del mito (2005, p. 184). La autora destaca (2005, pp. 187-188), como Swift (cf. n. 22), el hecho de que una de las características más sobresalientes del parthéneion es la separación del grupo de un individuo y que la participación de Hypermestra como parte del coro, irreconocible dentro del grupo pero sabida por la audiencia, resultaría fundamental en el desarrollo de la trilogía. A ello, agrega (2005, p.189) la relevancia de Amímone como protagonista del drama satírico, la segunda de las Danaides en ser removida del grupo: "Balancing Hypermestra's experience of a mortal marriage, Amymone's story would have brought the other element of the typical maiden's storyunion with a god-into the complete tetralogy." A pesar de su valiosa contribución para la interpretación de Suplicantes, Murnaghan tampoco analizó las odas corales de la obra.

24 De las cinco odas corales de la obra, no solo la inicial, sino también la cuarta (vv. 776-823), interacciona con el treno. La cuarta oda es, precisamente, la inmediatamente previa a la que interacciona con el himeneo y está, por lo tanto, en la memoria reciente del espectador, que acaba de presenciar el temor por la unión forzada con los hijos de Egipto y atestigua en la oda final la posibilidad de otra unión, consentida, con los ciudadanos de Argos. Para el análisis de la interacción genérica en la cuarta oda, cf. Fernández Deagustini (2016).

25 Este es el caso, por ejemplo, del ritual de arkteîa en Brauron. Cf. Swift (2010, p. 196).

26 Desde la perspectiva que propone la oda final, los Egipcios representan un modelo inapropiado de relaciones sexuales, en contraste con el saludable modelo encarnado por los guardias. Analizar el componente trenódico como parte del parthéneion induce a percibir la situación de las Danaides a través del filtro de la transición femenina y a comparar a su raptor/perseguidor con el casamiento legítimo y deseado que una parthénos debía esperar. Cf. el ya citado artículo (n. 19) sobre sexualidad y política, Fernández Deagustini (2019a).

27 Como señalamos en Fernández Deagustini (2019a) y en otros trabajos de investigación posteriores aún inéditos (Fernández Deagustini 2019b, 2019c), el tema de la unión con el hombre se coloca en Suplicantes en términos mucho más complejos que la categórica oposición rechazo/aceptación, del matrimonio, dado que se encuentra complicado con el tema de la violencia masculina, la falta de consentimiento de la unión y el peligro de una violación inminente. Respecto del itinerario ritual que, según mi propuesta, trama la obra, estas dificultades se integran magistralmente a la coralidad, permitiendo reflexionar y polemizar sobre cuestiones que hacen a las preocupaciones del género femenino y la construcción de la autoridad masculina. Como aclaré previamente (n. 21), la sinuosidad del itinerario no altera el perfecto equilibrio que presentan la oda inicial y la final aquí analizadas.

28 Precisamente, el mito del ruiseñor, presente en una de las secciones trenódicas de la oda inicial que refiere al mito de Procne, compara el lamento femenino con el de las aves, es decir, con un modelo del reino animal. El paradigma alude al potencial destructivo (inculto, salvaje) inherente al canto trenódico de las protagonistas, orientando al espectador a percibir la conducta de las Danaides como una actitud problemática, y no simplemente como una respuesta a su situación personal. De este modo, la perversión de la norma genérica convencional no sólo sirve para caracterizar a las protagonistas como figuras extraordinarias, sino para marcar los efectos destructivos que puede alcanzar la transgresión. Además, el mito es particularmente poderoso porque se sustenta en la cultura performativa/ritual en la que la audiencia se encuentra inmersa.

29 La aseveración no pretende involucrar el extenso debate acerca de si es posible considerar a Argos como un "alter-espacio" de Atenas. Atenas no constituye un espacio dramático, pero la obra se representa en Atenas frente a un público ateniense.

30 Zeitlin (1990, p. 104) compara y contrapone los patrones genéricos en Suplicantes y Siete contra Tebas y sostiene: "In the case of the Suppliants, the female is the focus of interest, and the issue is not war, the exemplary masculine activity in which the warrior may win his renown, but rather marriage, the critical event of female life which effects her passage to social adulthood." Swift (2010, pp. 249-250) da cuenta de la trascendencia de este proceso en la vida femenina desde la perspectiva lírica: "Unlike partheneia, hymenaios was not an exclusively female experience, for marriage was an important transition in the life of a man as well as a woman. However, while marriage may have been a telos for a man, 
it was not the only telos: men were expected to become politically active citizens and warriors as well as husbands and fathers. For a woman, marriage and the bearing of children was the ultimate focus and goal of her life, and it is therefore unsurprising that hymenaios focuses more on the experience of the bride than of her new husband".

31 Afirma Zeitlin (1990, p. 106): "the problem of separation from the father and his far-reaching authority is a crucial factor in their [the Danaids]dramatic situations”. Por su parte, Rysman (1989, p. 4) sostiene: “...Aeschylus' wish to stress the excessive attachment of the daughters to their father". Desde nuestro punto de vista, es necesario descartar las interpretaciones de corte psicológico. El vínculo padre-hijas refleja el hecho de que las Danaides, como mujeres, deben estar siempre acompañadas, en un espacio público, por una figura masculina. Por su condición de vírgenes, aún les corresponde la protección del padre.

32 Seaford (1987, p. 106). Nuestro análisis pone en duda la hipótesis del autor sobre Suplicantes, pues, sin contemplar las odas de manera integral, Seaford se atreve a afirmar que, en el caso de las Danaides, "the prevailing negative element is not the death of the bride but her hostility to the groom” (p. 107). La interacción genérica con el treno es clave para refutar su posición. Las amenazas de suicidio y otras referencias a la muerte aparecen sucesivamente, demostrando que el elemento negativo de la muerte de la novia no es menor que el de la hostilidad al varón. Según Zeitlin (1988, p. 232), "C'est le mariage qui civilise la femme, très littéralement, qui la dompte, car le mariage dans l'usage grec est perçu comme un joug qui sub-jugue et domestique. La jeune fille nubile est associée à de jeunes animaux folâtres qui courent librement; elle est associée aux espaces au-delà des frontières et à Artémis, déesse du monde sauvage”.

33 Zeitlin (1988, p. 238): “Au plan social, la virginité est un état liminal temporaire qui doit être préservé puis abandonné au moment opportun et dans les circonstances opportunes pour le $\tau \dot{\varepsilon} \lambda \circ \varsigma$ du mariage et de la fécondité. En tant qu'état permanent, la virginité n'est un attribut que des déesses". 